\title{
A study of association between genetic markers in candidate genes and reproductive traits in one generation of a commercial broiler breeder hen population
}

\author{
IC Dunn ${ }^{1}$, YW Miao ${ }^{1}$, A Morris ${ }^{2}$, MN Romanov ${ }^{1,3}$, PW Wilson ${ }^{1}$ and D Waddington ${ }^{1}$ \\ ${ }^{1}$ Roslin Institute, Roslin, Midlothian EH25 9PS, Scotland; ${ }^{2}$ The Cobb Breeding Company, East Hanningfield, Essex CM3 8BY, UK
}

\begin{abstract}
Markers of alleles for three physiological candidate genes for reproductive traits, growth hormone (GHR), gonadotropinreleasing hormone receptor (GNRHR) and neuropeptide $Y$ (NPY) were assessed for the association with the total egg production, number of double-yolked eggs and age at first egg in a single generation of a broiler breeder (Gallus gallus) pedigree dam line. Single-nucleotide polymorphisms and deletions were detected in the GHR, GNRHR and NPY genes. Genotypes were identified using a PCR-RFLP assay. The frequency of restriction enzyme $+/-$ alleles in the population was for GHR $0.68(\mathrm{Nspl}-)$ and $0.32(\mathrm{Nspl}+)$, for NPY 0.78 (Dral +) and 0.22 (Dral-) and for GNRHR 0.54
\end{abstract}

$(B p u 1102 \mathrm{I}+)$ and 0.46 (Bpu1102I-). Trait data from a total of 772 hens in 67 sire families from one generation of the pedigree dam line were recorded. However, the analysis used only the offspring of heterozygous sires to reduce the influence of selection and genetic background $(n=33$ sire families for GHR; $n=14$ sire families for NPY; $n=36$ sire families for GNRHR). A dominance effect of NPY on age at first egg and an additive effect of GNRHR on the number of double-yolked eggs were found $(P<0.05)$.

Heredity (2004) 92, 128-134, advance online publication, 17 December 2003; doi:10.1038/sj.hdy.6800396

Keywords: Gallus gallus; candidate genes; association; reproduction; SNP

\section{Introduction}

There are increasing amounts of information from whole genome scans (Milan et al, 2000), from natural mutants (Reddy and Siegel, 1977) and from the relationship between gene expression and trait (Rothschild et al, 1996) on the identity of genes that control traits of economic importance in farm animals.

However, unless it is possible to select for alleles of those genes that enhance performance in commercial lines the information will not be of practical use. In this study, we have selected candidate genes derived from the knowledge of reproductive physiology and tested whether these genes showed an association with reproductive performance in commercial poultry lines. A number of successes have been claimed for the physiological candidate gene approach to explain trait variance (eg Fotouhi et al, 1993; Rothschild et al, 1996; Sourdioux et al, 1996; Urbanek et al, 1999).

We applied the candidate gene approach to reproductive performance of broiler chickens. Broiler chickens have been selected with great success to improve the yield and the efficiency of meat production (Emmerson, 1997). This has not improved the reproductive efficiency. Selection for growth has been negatively correlated with

Correspondence: IC Dunn, Roslin Institute, Roslin, Midlothian EH25 9PS, Scotland. E-mail: Ian.Dunn@bbsrc.ac.uk

${ }^{3}$ Current address: Department of Microbiology and Molecular Genetics, 2209 Biomedical Physical Sciences, Michigan State University, East Lansing, MI 48824-4320, USA.

Received 27 September 2002; accepted 10 October 2003 aspects of reproductive performance, notably the occurrence of abnormal ovarian hierarchies (Hocking et al, 1987). This results in increased numbers of double-yolked eggs due to the simultaneous ovulation of two or more nonviable ova. Broiler breeders also have a relatively rapid decline in egg production, accompanied by sporadic cessation of lay (Sharp et al, 1992). Reproductive traits are relatively easily measured but can only be directly assessed over a period following sexual maturity; however, in the broiler industry, selection on growth characteristics is made before sexual maturity. Markerassisted selection for reproductive traits could usefully augment selection based only on dam performance. Reproductive traits offer, therefore, both a convenient model to appraise the application of association analysis of candidate genes in a commercial population and a potential application if markers are discovered.

The numbers of genes that are known to control reproduction are small but their individual effects are, in most cases, large. This is because the method of their discovery has often been due to the observation of the large effects that removal or mutation have on an animal's function. From such genes we have selected our candidate genes. The growth hormone (GHR)insulin-like growth factor-I (GH-IGF1) system controls the number of follicles in the avian ovary that are recruited to the rapid growth phase (Williams et al, 1992; Roberts et al, 1994) and a natural GHR mutation alters the ovulation rate (Reddy and Siegel, 1977). It is also known that the GH-IGF1 system has been modified as a result of selection for improved growth rate (Goddard et al, 1988). Thus, GHR was chosen as a candidate gene that might be 
associated with laying performance, or double-yolked eggs (Hocking et al, 1994). In addition, studies have demonstrated an association between GHR and egg production (Kuhnlein et al, 1997; Nagaraja et al, 2000).

The rapid decrease in ovarian activity in broiler breeders after the start of lay is a consequence of decreased gonadotrophin secretion (Sharp et al, 1992), resulting from decreased gonadotrophin-releasing hormone (GNRH) secretion. The expression of GNRH in the hypothalamus is decreased when gonadotrophin release is decreased (Dunn et al, 1996; Dunn and Sharp, 1999). GNRH stimulates the release of gonadotrophins from the pituitary through its receptor (GNRHR) (Sun et al, 2001a). GNRH and its receptor are therefore the start of the cascade that produces the appropriate growth, maturation and maintenance of the gonads. For these reasons, both GNRH and GNRHR were selected as candidate genes for the control of reproductive activity.

Neuropeptide $\mathrm{Y}$ (NPY) is known to influence the release of GNRH from the median eminence (Contijoch et al, 1993) and is critical in controlling food intake in birds, possibly matching satiety to reproductive activity and the timing of puberty (Kuenzel and Fraley, 1995). The NPY gene might produce markers for the age of the onset of lay and, through its role in the control of ovulation, influence egg production rate.

\section{Materials and methods}

\section{Experimental design and phenotypic measurement}

Birds from a pedigree broiler dam line were housed at 16 weeks of age in pens containing between 12 and 14 birds, and were fed a restricted diet to ensure that the body weight did not exceed $\sim 3.8 \mathrm{~kg}$ at 60 weeks of age as detailed in the Cobb 500 breeder management guide (Cobb Breeding Company, East Hanningfield, UK). Prior to that age, birds were reared on ad libitum feeding to 7 weeks of age and thereafter those birds selected for their growth characteristics were fed on a modified restricted diet aimed to gain the target weight of $3.17 \mathrm{~kg}$ at 26 weeks of age. Diet composition and lighting were all according to the Cobb 500 breeder management guide. The study population was three flocks, each of which were produced from seven consecutive hatches. Data on egg production including total egg production, age at first egg and number of double-yolked eggs were collected daily using trap nests to identify individual birds. The data for individual hens were collated over a 7-month period and recording commenced at 22 weeks of age. As all birds in each flock were treated the same despite differences in the hatch dates, this may have contributed to variance due to hatch. DNA and trait data were available from 772 animals. Information was also available for each bird on hatch, flock and sire and dam. There were 67 sire families. Sires could contribute to a maximum of three flocks depending on their age and the numbers of their daughters surviving culling on growth performance. In reality, only six sires contributed to all three flocks. One sire contributed to only flock 1, 15 only to flock 2 and 28 only to flock 3 . Two contributed to flock 1 and 2, one to flock 1 and 3 and 14 to flock 2 and 3 . Not all sire families were used in the analysis, only the offspring of heterozygous sires were used. This substantially reduced the amount of data, but gave marker effects estimated within families, and was therefore less likely to be affected by other background genetic differences between sires. These may lead to falsepositive associations between the candidate gene and the primary trait, which might occur, even when the candidate gene and the true trait gene are on different chromosomes, for example, when two genes are sufficiently close to genes descended from a population founder, which have both been under selection for a second, desirable trait. In addition, there may be other QTLs for the primary trait. The within-sire analysis will remove some of the effects of these QTLs when their allele frequencies are not balanced for the two candidate gene alleles across sires. At the beginning of the experiment, only some of the parental genotypes were available. It was possible, however, to infer further parental genotypes using the offspring genotypes because of the large sire families (mean $=11.5$ ). The number of sire families available was 14 for NPY, 36 for GNRHR and 33 for GHR. Only birds with complete records were included in the analyses.

\section{DNA preparation}

Red blood cells were stored at $4^{\circ} \mathrm{C}$ in 96-well plates. DNA was prepared using the GFX system (Amersham Pharmacia Biotech UK Ltd, Little Chalfont, UK) adapted for avian blood by using only $8-10 \mu \mathrm{l}$ whole blood mixed in $100 \mu \mathrm{l}$ phosphate-buffered saline taken directly into the extraction buffer. To maximise recovery, a double elution into $220 \mu \mathrm{l}$ of TE was performed.

\section{Determination of genomic sequence}

Unlabelled oligonucleotides (Table 1) (Cruachem Ltd, Glasgow, UK) were used in the PCR amplification of genomic DNA for sequencing prior to the design of oligonucleotides (Table 2) for single-nucleotide polymorphism (SNP) detection and genotyping. The PCR conditions for amplification were: $200 \mu \mathrm{M}$ dNTPs, $0.5 \mathrm{U}$ of Taq polymerase (Roche Diagnostics Ltd, Lewes, East Sussex, UK), $100 \mathrm{pmol}$ of each primer, $100 \mathrm{ng}$ genomic DNA in a $20 \mu \mathrm{l}$ reaction containing $1.5 \mathrm{mM} \mathrm{MgCl}_{2}, 10 \mathrm{mM}$ Tris- $\mathrm{HCl}$ (pH 8.3), $50 \mathrm{mM} \mathrm{KCl}$. The PCRs were carried out at $94^{\circ} \mathrm{C}, 4 \mathrm{~min}$ for one cycle; $94^{\circ} \mathrm{C}, 20 \mathrm{~s} ; 56^{\circ} \mathrm{C}, 20 \mathrm{~s}$; $74^{\circ} \mathrm{C}$, $20 \mathrm{~s}$ for 40 cycles on a Hybaid Omnigene thermocycler (Thermo Life Sciences, Basingstoke, UK).

Table 1 PCR primers used for determining genomic sequence

\begin{tabular}{lll}
\hline Name & Sequence & Position, accession number \\
\hline GHRex5 & 5'-ACGAAAAGTGTTTCAGTGTTGA-3' & Bases 358-379, M74057 \\
GHRex6 & 5'-GTGGATCCCATCGTACTTGA-3' & Bases 461-480, M74057 \\
GnRHRE1 & 5'-GGATGCTGAGCACTTGTGCT-3' & (YM Sun, personal communication) \\
GnRHRE2 & 5'-TGAGTGGCCGAGGTGTTG-3' & Bases 133-150, AJ304414 \\
\hline
\end{tabular}


Detection of polymorphisms

The majority of polymorphism detection was carried out by Base Excision Sequence Scanning (T-Scan, Epicentre Technologies; Cambio Ltd, Cambridge, UK) (Hawkins and Hoffman, 1999) and the remainder by bulk amplified restriction fragment length polymorphism detection. Detection was carried out on 30 sires from the pedigree dam line. A diagnostic restriction digest of the PCRamplified product was performed to confirm the allele frequency for all polymorphisms.

\section{Genotyping assay}

Genotyping assays for GHR, NPY and GNRHR were based on the presence or absence of a restriction site at the polymorphic sites in PCR-amplified DNA fragments (PCR-RFLP). All genotyping PCRs differed from the standard protocol by the inclusion of one-fifth volume of $5 \times$ gel loading dye $(16.5 \%$ sucrose, $0.01 \%$ bromophenol blue). Other differences from our standard PCR conditions were the inclusion for NPY of $2 \mathrm{mM} \mathrm{MgCl}_{2}$ and for GNRHR 5\% DMSO.

For RFLP analysis, $5 \mu \mathrm{l}$ of PCR product was digested according to the manufacturer's protocol. All digestions were performed overnight at $37^{\circ} \mathrm{C}$. After digestion with the discriminating restriction enzyme, the products were separated on a $3 \%$ agarose gel and the genotypes identified according to the resolved products; either a single full-length uncut product, two products of digestion or, in the case of heterozygotes three products, full-length uncut and two digested products.

\section{Association analysis}

Numbers of double-yolked eggs were approximately distributed as an overdispersed Poisson variable, and were analysed as a generalised linear model with parameters estimated on the logarithmic scale. Other variables were shifted and rescaled using a log transformation to give approximate normality and equality of variance. The total number of eggs was negatively skewed, and was analysed as the log of total number of eggs subtracted from a hypothetical upper limit of 150. Age at first egg was positively skewed, and had a value of 150, coincidentally, subtracted before taking logarithms. The effects of hatch $(h)$, flock $(f)$ and their interaction together with sires (s) and the marker genotypes $(m)$ were fitted, as fixed effects, to the expectation of the transformed responses $(y)$, as

$$
E\left(y_{i j k l}\right)=s_{i}+h_{j}+f_{k}+h f_{j k}+m_{l}
$$

Linear models were fitted by regression analysis and generalised linear models by iteratively reweighted least squares, followed by Student's $t$-tests to assess possible marker effects. Additive effects of markers were estimated as the differences between homozygote means, and dominance effects as the difference between twice the heterozygote mean and the sum of the homozygote means. The exception was GHR, because it is sex linked and dams carry only one allele. The collective results of the 15 tests of trait and marker combinations were assessed by a Bonferoni 5\% significance threshold of $P=0.05 / 15=0.0033$, conservatively assuming the 15 tests to be independent.

\section{Results}

Genomic sequence, polymorphic loci and allele frequency The GHR intron 5 was cloned and sequenced (Genembl accession AJ506750). Two SNPs were discovered that were linked, both cytosine-thymidine transversions in intron 5. One was chosen to develop an assay (Table 3). In the 457 offspring of heterozygous sires, the genotype frequency for $\mathrm{Nsp}$ - was 0.63 . This exceeds the anticipated figure of 0.5 for a sex-linked gene, suggesting that the GHR locus may be under some selection pressure.

A 4-bp deletion/insertion about 700 bases upstream of the NPY transcription start site was characterised (Table 3). In the offspring of heterozygous sires, the frequencies of the alleles were close to that predicted if the males were crossed randomly with dams from the whole population. Genotypes did not differ from the expected Hardy-Weinberg equilibrium.

Intron 1 of the GNRHR contained an SNP that was used for genotyping (Table 3). In the offspring of

Table 2 PCR primers used for SNP detection and the genotyping assays

\begin{tabular}{lll}
\hline Name & Sequence & Position, accession number \\
\hline GHRex5 & $5^{\prime}$-ACGAAAAGTGTTTCAGTGTTGA-3' & Bases 1-22, AJ506750 \\
GHR424F & $5^{\prime}$-TTTATCCCGTGTTCTCTTGACA-3' & Bases 741-762, AJ506750 \\
GnRHRmap5 & $5^{\prime}$-GGTGTCTGAGGCTCATTTCA-3' & Bases 282-301, AJ506779 \\
GnRHRmap8 & $5^{\prime}$-TAGCAATCGCTTGCCCAGA-3' & Bases 682-700, AJ506779 \\
NPYmap9 & $5^{\prime}$-TCTCAGAGCTCCAACGTATGA-3' & Bases 415-435, M87298 \\
NPYmap10 & 5'-ATATTTCTGTGCCTGAACAACA-3' & Bases 645-666, M87298 \\
\hline
\end{tabular}

Table 3 Genomic sequence, polymorphic loci and allele frequency

\begin{tabular}{|c|c|c|c|c|c|c|}
\hline Gene & GenEMBL accession & Position & PCR primers & Diagnostic enzyme & Type of polymorphism & Frequency of rarer allele \\
\hline GHR & AJ506750 & 571 & $\begin{array}{l}\text { GHREX5 } \\
\text { GHR424F }\end{array}$ & Nsp I & $\mathrm{C} / \mathrm{T}$ transversion & $N s p \mathrm{I}+0.32$ \\
\hline NPY & M87298 & $494-499$ & $\begin{array}{l}\text { NPYMAP9 } \\
\text { NPYMAP10 }\end{array}$ & DraI & 4 bp deletion & DraI-0.22 \\
\hline GNRHR & AJ506779 & 537 & $\begin{array}{l}\text { GNRHRMAP5 } \\
\text { GNRHRMAP8 }\end{array}$ & Ври1102I & $\mathrm{C} / \mathrm{T}$ transversion & Ври1102I-0.46 \\
\hline
\end{tabular}


Table 4 Back-transformed means (SEs) for the offspring of heterozygous sires ${ }^{a}$

\begin{tabular}{|c|c|c|c|c|c|}
\hline Candidate gene & Genotype & Age at first egg & Number of eggs & Number of double-yolked eggs & No. of observations \\
\hline \multirow[t]{2}{*}{ GHR } & NspI+ & $189.0(3.3)$ & $99.5(5.8)$ & $0.66(0.27)$ & 143 \\
\hline & NspI- & $189.6(3.3)$ & $98.8(5.8)$ & $0.57(0.24)$ & 247 \\
\hline \multirow[t]{3}{*}{ GNRHR } & Ври1102I-/- & $187.3(2.8)$ & $92.8(6.6)$ & $1.00(0.68)$ & 87 \\
\hline & Ври1102+/+ & $187.5(2.8)$ & $95.3(6.2)$ & 1.59 (1.06) & 120 \\
\hline & Ври $1102+/-$ & $188.4(2.7)$ & $91.0(6.4)$ & $1.22(0.81)$ & 193 \\
\hline \multirow[t]{3}{*}{ NPY } & DraI+/+ & $193.8(6.2)$ & $92.9(10.8)$ & $0.41(0.25)$ & 62 \\
\hline & DraI-/- & $198.0(7.4)$ & 84.9 (13.4) & $0.51(0.32)$ & 33 \\
\hline & DraI+/- & $189.4(5.7)$ & 95.5 (10.6) & $0.54(0.32)$ & 88 \\
\hline
\end{tabular}

${ }^{a}$ Excluding birds with either incomplete records or untyped for candidate gene. Standard errors for transformed values are approximated as $\mathrm{SE}(\log$ mean)exp(log mean). Figures in bold indicate genotype trait associations that were significant (Table 5).

Table 5 Association analysis fitting the offspring of heterozygous sires

\begin{tabular}{|c|c|c|c|c|}
\hline Gene loci & & $\log A F E$ & $\log N E$ & Log No DYE \\
\hline GHR & & $\begin{array}{l}0.014(0.043) \\
t_{337}=0.32\end{array}$ & $\begin{array}{l}0.013(0.058) \\
t_{337}=0.23\end{array}$ & $\begin{array}{l}-0.132(0.159) \\
t_{337}=-0.83\end{array}$ \\
\hline GNRHR & $\begin{array}{l}\text { Additive } \\
\text { Dominant }\end{array}$ & $\begin{array}{l}0.006(0.051) \\
t_{344}=0.12 \\
0.052(0.072) \\
t_{344}=0.73\end{array}$ & $\begin{array}{l}-0.045(0.077) \\
t_{344}=-0.58 \\
0.108(0.109) \\
t_{344}=0.99\end{array}$ & $\begin{array}{l}0.459(0.196) \\
t_{344}=2.34^{*} \\
-0.077(0.283) \\
t_{344}=-0.27\end{array}$ \\
\hline NPY & $\begin{array}{l}\text { Additive } \\
\text { Dominant }\end{array}$ & $\begin{array}{l}0.087(0.092) \\
t_{148}=0.95 \\
-0.307(0.124) \\
t_{148}=-2.49^{*}\end{array}$ & $\begin{array}{l}0.125(0.123) \\
t_{148}=1.02 \\
-0.226(0.166) \\
t_{148}=-1.37\end{array}$ & $\begin{array}{l}0.226(0.334) \\
t_{148}=0.68 \\
0.318(0.466) \\
t_{148}=0.68\end{array}$ \\
\hline
\end{tabular}

Model: sire+hatch+flock+hatchxflock+markers. Results are shown as estimated effects (SEs) and $t$ values with their degrees of freedom. $\log A F E=\log \left(\right.$ age at first egg-150); $\log N E=\log \left(150-\right.$ number of eggs); $\log$ NoDYE $=\log \left(\right.$ number of double-yolked eggs). ${ }^{*} P<0.05$.

heterozygous sires, the allele frequencies were identical to those in the whole population and almost identical to that predicted if the males were crossed randomly with dams from the whole population. The genotype frequency did not differ from Hardy-Weinberg equilibrium.

Despite using 19 primer pairs covering $46 \%$ of the $6.4-$ $\mathrm{kb}$ of the known GNRH gene sequence and its upstream region (Dunn et al, 1993), no polymorphic sites were detected in the 30 individuals.

\section{Heritability}

Heritability was estimated from the data of all offspring for age at first egg, 0.17; for total egg production, 0.09 (both on the log scale); and for double-yolked eggs 0.25 (on the observed scale). The low values for total egg production were similar to those observed in other studies in broiler breeders (Koerhuis and McKay, 1996) and probably reflects the number of factors that influence the total egg production.

\section{Results of association analysis}

The back-transformed means together with approximate standard errors from the model fitted on the logarithmic scale of the analyses are presented in Table 4 for the offspring of heterozygous sires. These back-transformed means allow adjustments for possible imbalances across the marker alleles in the number of observations for flock and hatch when these affected a trait. Most markedly, there was a decline in the age at first egg with hatch. Analysis for genes used different subsets of the 772 animals. Concentrating on heterozygous sires means using about $1 / 2$ of the data for GHR and GNRHR and only about $1 / 4$ of the data for NPY. The observed differences between GHR alleles were small for all three traits, but even with the reduced number of observations we were able to detect associations (at $P<0.05$ ) of a trait with the GNRHR and NPY markers in single analyses.

Thus, an additive effect was observed for GNRHR and the number of double-yolked eggs, and a dominance effect of NPY and age at first egg (Table 5). However, when considered collectively as 15 tests, these combinations did not achieve significance at 5\%. The GNRHR Bpu1102+ / + genotype had the greatest number of double-yolked eggs at 1.59 compared to 1.00 for Bpu1102-/- on the back-transformed scale (Table 4), with the Bpu1102+/- genotype intermediate on the back-transformed scale. The NPY DraI + /- heterozygotes had the earliest age for laying their first egg at 189.4 days compared to 198.0 days for the DraI-/genotypes and 193.8 for the DraI $+/+$ genotype (Table 4).

\section{Discussion}

The associations detected by the analysis within the single generation of hens from the heterozygous sires suggest that the GNRHR gene and the NPY genes play a role in controlling the traits of double-yolked eggs and 
age at first egg, respectively. For GNRHR and number of double-yolked eggs, the sizes of the positive effects relative to the homozygous genotype Bpu1102I-/ - were 0.22 for the heterozygote Bpu1102I $+/-$ and for the homozygote Bpu1102I + / + 0.59 (Table 4). For NPY, the reduction in age at first egg of the heterozygote $\mathrm{DraI}+/-$ compared to the homozygote DraI-/ - was 8.6 days and for the homozygote DraI $+/+4.2$ days (Table 4 ).

In the case of GNRHR and double-yolked eggs, if only animals with the Bpu1102I-/ - genotype were selected in this line, we would expect an improvement in the overall flock performance of 0.31 usable eggs per hen in view of the frequency of this allele $(0.4)$. The overdominance effect observed for NPY and age at first egg would be harder to use in practice. However, the establishment of lines carrying only one allele could be used to produce heterozygous hens in the final breeder cross. This would give an overall decrease in the age at first egg of the flock of 3.2 days/hen. In practice, the benefits of earlier age at first egg must be balanced with problems of reduced egg size and possibly numbers of double-yolked eggs, but a reduction may be beneficial to enhance efficiency. There was a small, expected negative effect of age at first egg on the number of double-yolked eggs, but this did not change the association with GNRHR.

Association studies cannot determine if the gene allele markers (SNPs and RFLPs) are responsible for the variation in a trait or whether it is due to a closely linked locus. However, there is good reason to believe that these genes would influence the traits in chickens. The GNRHR is expressed in the pituitary, the gonads and the hypothalamus and has the pharmacological profile of an avian GNRH receptor (Sun et al, 2001b). Since the GNRHR occurs in the gonads as well as the pituitary, its effect might occur at the level of the ovary, possibly by affecting cell proliferation and apoptosis as suggested in mammals (Takekida et al, 2000).

NPY induces precocious puberty in chicks (Fraley and Kuenzel, 1993) and controls feed intake (Kuenzel and Fraley, 1995; Boswell et al, 1999). In mammals, the NPY neurones are targets for leptin, which may be a mechanism that metabolic factors 'gate' entry to puberty (Cheung et al, 1997). NPY also has an established role in controlling GNRH secretion during the preovulatary surge of gonadotrophins (Contijoch et al, 1993). Either might have an effect on age at first egg and it is tempting to speculate that each allele might have a favourable role for each function. It is hard, however, to envisage a mechanism whereby the expression of the two alleles of NPY together produces advancement in age at first egg as observed.

Feng et al (1997) observed a negative relationship in layer-type hens between the number of eggs and age at first egg, which was different between GHR genotypes. We found no such effect in the broiler line used in this study, although there was a weak negative correlation between these traits. Owing to the likely role of the $\mathrm{GH}$ IGF1 system in producing polyfollicular ovaries at the onset of lay, a possible association between GHR with the number of eggs produced in the first two months was also examined, but without success. Feng et al (1997) demonstrated a significant association with age at first egg and alleles of GHR that may be worth investigating along with other components of the GH-IGFI system.
Studies seeking correlations between alleles of candidate genes and quantitative traits have frequently used single-generation comparisons (eg Feng et al, 1997, 1998; Nagaraja et al, 2000). Like these studies, when we fit a model excluding sires, we find a large number of statistically significant associations. Four significant effects $(P<0.05)$ are observed: for GHR and number of double-yolked eggs $(t=-2.40$, df 596), GNRHR and number of double-yolked eggs (additive; $t=2.18$, df 612), GNRHR and number of eggs (dominance; $t=2.36$, df 612) and NPY and age at first egg (additive; $t=2.05, \mathrm{df}$ 636). Only the additive effect for GNRHR and number of double-yolked eggs is consistently significant between the test for association using all animals and those using only heterozygous sires. NPY and age at first egg, although significant in both tests, is significant as an additive effect in the case using all animals and as a dominance effect when only heterozygous sires offspring are used. In a population undergoing strong selection, as here, in order to avoid possible spurious associations we used comparisons between half sibs within heterozygous sires to control for some of the general genetic background differences between sires. This would also reduce false association due to cosegregation with loci under selection. Despite its potential loss of power from only using a subset of the data, we still observe two significant associations for two of the analyses of the nine combinations of candidate gene and reproductive trait, but not when the 15 tests of genetic effects are considered together in controlling experiment-wide error. Given that the genes were chosen a priori on the basis of their known effects, there may be some debate about the need for such corrections.

In this study, parental genotypes were supplemented by inference from the offspring genotypes. Sires falsely classified as heterozygous would be expected to dilute possible additive effects, while inflating possible dominance effects. This would be most likely with GNRHR, but no dominance effects are observed.

A more sophisticated allowance for a common genetic background is to fit an animal model giving correlations between individual observations based on their expected additive genetic correlations (eg Rothschild et al, 1996; Drogemuller et al, 2001). This should help to correct for a general genetic background, particularly with deep pedigrees, although there might still be some contribution to gene effects from between-family comparisons. Another approach for additive effects would be to parameterise the marker allele count to give betweenand within-family estimates, and test whether they are consistent by allowing a combined estimate with more power (Hernandez-Sanchez et al, 2003). This may be carried out by creating two covariates for allele count, one for the family (sire) mean and one for the deviations from the family mean and fitting them in addition to sires in an REML analysis. In the presence of additional unbalanced fixed effects, these estimates will not be exactly independent, but may have a small correlation. For our data, this combined analysis suggested no significant additive effects for any combination of markers and traits. The most notable effect was for GNRHR on the number of double-yolked eggs (allelesubstitution effect $=0.37, S E=0.20$ ). The estimate for between-sire families was $0.19(\mathrm{SE}=0.52)$ and within-sire families was $0.39(\mathrm{SE}=0.22)$ from the fitting of a 
generalised linear mixed model (Breslow and Clayton, 1993) allowing for the random effect of sire and the fixed effects of hatch, flock and their interaction. The correlation between the estimates was -0.07 and the standard error of their difference was 0.58. In this case, the additional information and the additive effect estimate from between-family comparisons were small, and not influential. The power to detect a discrepancy between the two estimates was poor.

Heritability values for AFE and DYE are larger than for egg production, which may explain why we detected an association with genes potentially involved in the control of these traits. There is no reason to believe that the accuracy of trait measurement and the effect of environment should not influence the estimate of association as it would for any other analysis.

It will ultimately be possible to combine in a selection index a number of molecular markers with a small effect to improve reproductive performance. This will depend on the cost of marker-assisted selection and the negative effects of including extra indices for selection on other traits alongside the net improvement in productivity.

\section{Acknowledgements}

This study was funded by DEFRA LS2002 'Candidate genes for reproductive efficiency in broiler breeders'. MNR was supported by the Royal Society/NATO Postdoctoral Fellowship.

\section{References}

Boswell T, Dunn IC, Corr SA (1999). Hypothalamic neuropeptide $\mathrm{Y}$ mRNA is increased after feed restriction in growing broilers. Poult Sci 78: 1203-1207.

Breslow NE, Clayton DG (1993). Approximate inference in generalized linear mixed models. J Am Statist Assoc 88: 9-25.

Cheung CC, Thornton JE, Kuijper JL, Weigle DS, Clifton DK, Steiner RA (1997). Leptin is a metabolic gate for the onset of puberty in the female rat. Endocrinology 138: 855-858.

Contijoch AM, Malamed S, McDonald JK, Advis JP (1993). Neuropeptide Y regulation of LHRH release in the median eminence: immunocytochemical and physiological evidence in hens. Neuroendocrinology 57: 135-145.

Drogemuller C, Hamann H, Distl O (2001). Candidate gene markers for litter size in different German pig lines. J Anim Sci 79: 2565-2570.

Dunn IC, Beattie KK, Maney D, Sang HM, Sharp PJ, Talbot RT et al (1996). Regulation of chicken gonadotropin-releasing hormone-I mRNA in incubating, nest-deprived and laying bantam hens. Neuroendocrinology 63: 504-513.

Dunn IC, Chen Y, Hook C, Sharp PJ, Sang HM (1993). Characterisation of the chicken pre-progonadotrophin releasing hormone-I gene. J Mol Endocrinol 11: 19-29.

Dunn IC, Sharp PJ (1999). Increasing photoperiod in mature and peripubertal but not prepubertal chickens increases cGnRH-I mRNA content, a role for steroids? J Neuroendocrinol 11: $371-375$.

Emmerson DA (1997). Commercial approaches to genetic selection for growth and feed conversion in domestic poultry. Poult Sci 76: 1121-1125.

Feng XP, Kuhnlein U, Aggrey SE, Gavora JS, Zadworny D (1997). Trait association of genetic markers in the growth hormone and the growth hormone receptor gene in a White Leghorn strain. Poult Sci 76: 1770-1775.

Feng XP, Kuhnlein U, Fairfull RW, Aggrey SE, Yao J, Zadworny D (1998). A genetic marker in the growth hormone receptor gene associated with body weight in chickens. J Hered 89: 355-359.

Fotouhi N, Karatzas CN, Kuhnlein U, Zadworny D (1993). Identification of growth hormone DNA polymorphisms which respond to divergent selection for abdominal fat content in chickens. Theor Appl Genet 85: 931-936.

Fraley GS, Kuenzel WJ (1993). Precocious puberty in chicks (Gallus domesticus) induced by central injections of neuropeptide Y. Life Sci 52: 1649-1656.

Goddard C, Wilkie RS, Dunn IC (1988). The relationship between insulin-like growth factor-1, growth hormone, thyroid hormones and insulin in chickens selected for growth. Domest Anim Endocrinol 5: 165-176.

Hawkins GA, Hoffman LM (1999). Rapid DNA mutation identification and fingerprinting using base excision sequence scanning. Electrophoresis 20: 1171-1176.

Hernandez-Sanchez J, Visscher P, Plastow PG, Haley CS (2003). Candidate gene analysis for quantitative traits using transmission disequilibrium tests: the example of melanocortin 4receptor in pigs. Genetics 164: 637-644.

Hocking PM, Bernard R, Wilkie RS, Goddard C (1994). Plasma growth hormone and insulin-like growth factor-I (IGF-I) concentrations at the onset of lay in ad libitum and restricted broiler breeder fowl. Br Poult Sci 35: 299-308.

Hocking PM, Gilbert AB, Walker M, Waddington D (1987). Ovarian follicular structure of White Leghorns fed ad libitum and dwarf and normal broiler breeders fed ad libitum or restricted until point of lay. Br Poult Sci 28: 493-506.

Koerhuis ANM, McKay JC (1996). Restricted maximum likelihood estimation of genetic parameters for egg production traits in relation to juvenile body weight in broiler chickens. Livest. Prod. Sci 46: 117-127.

Kuenzel WJ, Fraley GS (1995). Neuropeptide Y: its role in the neural regulation of reproductive function and food intake in avian and mammalian species. Poult Avian Biol Rev 6: 185-209.

Kuhnlein U, Ni L, Weigend S, Gavora JS, Fairfull W, Zadworny D (1997). DNA polymorphisms in the chicken growth hormone gene: response to selection for disease resistance and association with egg production. Anim Genet 28: 116-123.

Milan D, Jeon JT, Looft C, Amarger V, Robic A, Thelander M et al (2000). A mutation in PRKAG3 associated with excess glycogen content in pig skeletal muscle. Science 288: 1248-1251.

Nagaraja SC, Aggrey SE, Yao J, Zadworny D, Fairfull RW, Kuhnlein U (2000). Trait association of a genetic marker near the IGF-I gene in egg-laying chickens. J Hered 91: 150-156.

Reddy PRK, Siegel PB (1977). Selection for body weight at eight weeks of age 14. Effects of the sex-linked dwarf gene. Poult Sci 56: 1004-1013.

Roberts RD, Sharp PJ, Burt DW, Goddard C (1994). Insulin-like growth factor-I in the ovary of the laying hen: gene expression and biological actions on granulosa and thecal cells. Gen Comp Endocrinol 93: 327-336.

Rothschild M, Jacobson C, Vaske D, Tuggle C, Wang LZ, Short T et al (1996). The estrogen receptor locus is associated with a major gene influencing litter size in pigs. Proc Natl Acad Sci USA 93: 201-205.

Sharp PJ, Dunn IC, Cerolini S (1992). Neuroendocrine control of reduced persistence of egg-laying in domestic hens: evidence for the development of photorefractoriness. J Reprod Fertil 94: 221-235.

Sourdioux M, Douaire M, Delabrosse Y (1996). DNA polymorphisms of lipogenesis genes and analysis of linkage with fatness in turkeys. Poult Sci 75: 1018-1026.

Sun YM, Dunn IC, Baines E, Talbot RT, Illing N, Millar RP et al (2001a). Distribution and regulation by oestrogen of fully processed and variant transcripts of gonadotropinreleasing hormone I and gonadotropin-releasing hormone receptor mRNAs in the male chicken. J Neuroendocrinol 13 37-49. 
Sun YM, Flanagan CA, Sellar R, Ott TR, Fromme BJ, Illing N et al (2001b). A chicken gonadotropin-releasing hormone receptor that confers agonist activity to mammalian antagonists. Identification of D-Lys(6) in the ligand and extracellular loop two of the receptor as determinants. J Biol Chem 276: 7754-7761.

Takekida S, Deguchi J, Samoto T, Matsuo H, Maruo T (2000). Comparative analysis of the effects of gonadotropin-releasing hormone agonist on the proliferative activity, apoptosis, and steroidogenesis in cultured porcine granulosa cells at varying stages of follicular growth. Endocrine 12: 61-67.

Urbanek M, Legro RS, Driscoll DA, Azziz R, Ehrmann DA, Norman RJ et al (1999). Thirty-seven candidate genes for polycystic ovary syndrome: strongest evidence for linkage is with follistatin. Proc Natl Acad Sci USA 96: 8573-8578.

Williams J, Sharp PJ, Goddard C (1992). The effects of growth hormone on ovarian follicular growth in the domestic hen. J Reprod Fertil, Abstract Series No., 9: 59. 